\title{
SODIUM ALUM.
}

By WARREN RUfUS SMITH.

Received November $21,1908$.

Sodium alum, $\left(\mathrm{Na}_{2} \mathrm{SO}_{4} \mathrm{Al}_{2}\left(\mathrm{SO}_{4}\right)_{3}, 2 \mathrm{H}_{2} \mathrm{O}\right)$, was made by several of the earlier observers but its existence has been questioned several times. One of the latest to deny the existence of this compound is Ostwald, who says that the potassium in ordinary alum may be replaced by caesium or rubidium but not by sodium or lithium. On the other hand, Auge ${ }^{2}$ and Wadmore ${ }^{3}$ have affirmed the existence of sodium alum. No one, however, has applied any criterion, other than analysis, to prove or disprove the existence of sodium alum as a definite chemical species. The experiments described below show that sodium and aluminum sulphates crystallize together, that the double salt formed is a chemical species, and that it is a true alum.

Whenever approximately equivalent amounts of sodium and aluminum sulphates are dissolved in water and made to crystallize at ordinary temperatures, octahedral crystals are obtained which, as shown by the analyses below, correspond in composition with the theoretical sodium alum. The best method of manufacturing this compound is to dissolve the materials in an amount of water sufficient to give a solution moderately supersaturated at ordinary temperatures, and then cool the solution and induce crystallization by stirring or by seeding. Small crystals will be obtained similar to "alum meal." If larger crystals are desired, they can be made by slow evaporation at ordinary temperatures. That this substance is a definite chemical species is proved by the fact that the composition does not vary when crystallized from solutions of varying composition. The first of the analyses below is that of material from a solution containing the two sulphates in equivalent proportions, the second, of material from a solution containing sodium sulphate in excess.

Found.

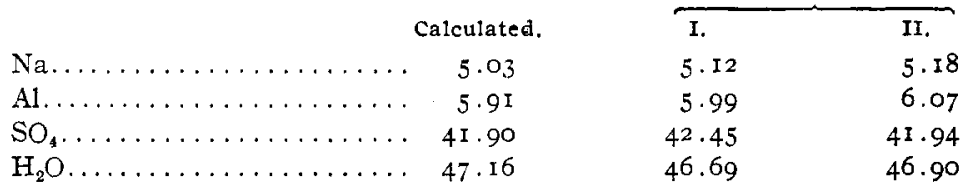

If the solution is made so strong that crystallization starts at a temperature much above $30^{\circ}$, instead of clear crystals of the alum, a mass of small crystals of aluminum sulphate is obtained. If these crystals are kept in contact with their mother liquor at laboratory temperatures for some time, crystals of sodium alum will appear, and, after some weeks, the entire mass will be changed to well-formed crystals of the alum. A

\footnotetext{
1 "Principles of Inorganic Chem.," Trans. by Findlay, p. 565.

${ }^{2}$ Compt. rend., I I0, II39.

${ }^{3}$ Proc. Chem. Soc, 2 I, 150.
} 
quantity of material which separated from a warm solution was filtered off, dried between filter papers, and analyzed, giving figures corresponding closely to aluminum sulphate with 16 per cent. anhydrous sodium sulphate. Other analyses of material obtained in a similar way gave similar figures varying more or less from the above proportion, showing that the mass is simply aluminum sulphate contaminated with sodium sulphate from the mother liquor. Ii sodium alum is kept in contact with its saturated solution at temperatures above about $30^{\circ}$, it is decomposed into an opaque finely divided mass which is probably aluminum sulphate. The exact temperature of the transition has not yet been determined. Some of these phenomena have been noted by other observers, but their true explanation has not been given. The reason why the existence of sodium alum has been questioned probably lies in the fact that it is not formed at temperatures much above $30^{\circ}$. Attempts. to prepare sodium chromium alum, sodium iron alum, and lithium aluminum alum by methods similar to those which give sodium aluminum alum were unsuccessful.

That sodium alum is a true alum is shown by the fact that it forms mixed and layer crystals with other alums. With ordinary potash alum such mixtures are not very easily obtained, probably on account of their different solubilities. However, after repeated trials, a quantity of material was obtained, a single crystal of which contained potassium and sodium in the ratio of four to one. On the other hand sodium alum readily forms layer crystals with chrome alum.

The solubility of sodium alum is given below. These figures were obtained as follows: a quantity of the salt and a quantity of water insufficient to dissolve it were placed in one bottle, in another was placed a quantity of the salt and a quantity of its solution saturated at a temperature higher than that at which the observation was to be made. These bottles were stoppered and rotated for about six hours in a bath. the temperature of which was constant to within about $0.04^{\circ}$. This bath was controlled by a thermostat similar to one described by Magnusson $^{1}$ which was found to be efficient under trying conditions. After rotation, about ro cc. of solution were withdrawn from each bottle by a pipette, transferred to a platinum dish, weighed, evaporated to dryness, and the residue heated to constant weight at $250^{\circ}$. On evaporating these solutions to dryness at a temperature below $100^{\circ}$, in several instances, a perfectly clear amorphous glassy residue was left, which on further heating gave an opaque mass like "burnt alum." This amorphous residue could be nothing but a solid solution of the two sulphates and water, as a specimen of it was found to contain about 30 per cent. water.

\footnotetext{
1. Phisic. Chem., II, 23.
} 
Grams Anhydrous Material Contained in roo Grams Solution.

\begin{tabular}{|c|c|c|c|c|}
\hline \multirow[b]{2}{*}{$10^{\circ}$} & \multicolumn{2}{|c|}{ From unsaturated solution. } & From supersaturated solution. & Average. \\
\hline & 26.86 & & 27.27 & 26.9 \\
\hline $15^{\circ}$ & 27.87 & & 28.00 & $27 \cdot 9$ \\
\hline $20^{\circ}$ & 29.06 & & 28.98 & 29.0 \\
\hline $25^{\circ}$ & 30.13 & & 30.13 & 30.1 \\
\hline \multirow[t]{3}{*}{$30^{\circ}$} & 31.49 & & $3 I .43$ & $3 \mathrm{I} \cdot 4$ \\
\hline & \multicolumn{2}{|c|}{ Grams $\mathrm{Na}_{2} \mathrm{SO}_{4} \mathrm{Al}_{2}\left(\mathrm{SO}_{4}\right)_{3}$ per $100 \mathrm{~g}$} & \multicolumn{2}{|c|}{ Grams $\mathrm{Na}_{2} \mathrm{SO}_{4} \mathrm{Al}_{2}\left(\mathrm{SO}_{4}\right)_{3} 24 \mathrm{H}_{2} \mathrm{O}$ per $100 \mathrm{~g}$} \\
\hline & Water. & Solution. & Water. & Solution. \\
\hline $10^{\circ}$ & 36.7 & 26.9 & $103 \cdot I$ & 50.8 \\
\hline $15^{\circ}$ & $38 \cdot 7$ & $27 \cdot 9$ & I I I 3 & $5^{2} \cdot 7$ \\
\hline $20^{\circ}$ & 40.9 & 29.0 & I 2 I $\cdot 4$ & 54.8 \\
\hline $25^{\circ}$ & $43 \cdot 1$ & 30.1 & 131.8 & 56.9 \\
\hline $30^{\circ}$ & 45.8 & $3 \mathrm{I} \cdot 4$ & 146.3 & $59 \cdot 4$ \\
\hline
\end{tabular}

\section{THE COLORIMETRIC ESTIMATION OF PHOSPHATES IN SOLU- TION WITH OTHER SALTS.}

By Clarence Estes.

Received November 6, 1908 .

In the course of experiments to determine the quantity of phosphorus in some samples of meat by the colorimetric method it soon became evident that the salts obtained in solution with the phosphates as the result of the oxidizing agents used interfered very seriously with the intensity of color. The influence of salts on the color was therefore given further study. Attention was given to those salts that are likely to be found present in practice, such as occur in soil extracts, plant extracts, and the salts resulting from the oxidation of organic matter, with sodium peroxide, magnesium nitrate, sodium carbonate and magnesium oxide, or a mixture of concentrated nitric and sulphuric acids. Altogether ten reagents were studied: namely, sodium nitrate, potassium nitrate, calcium nitrate, magnesium nitrate, sodium sulphate, potassium hydrogen sulphate, potassium ethyl sulphate, magn siumesulphate, sodium chloride, and nitric acid.

Solutions for comparison were prepared by diluting 2 or $4 \mathrm{cc}$. of a standard phosphate solution to $30 \mathrm{cc}$. A known quantity of a certain salt was then added and the solution left standing until the salt was completely dissolved. The color was then developed by adding $5 \mathrm{cc}$. each of nitric acid, sp. gr. I.07, and ammonium molybdate solution and diluting to $50 \mathrm{cc}$. After twenty minutes the color thus developed was compared with that of a standard phosphate solution containing the same quantities of phosphorus, ammonium molybdate, and nitric acid, but none of the salt. The quantities of nitric acid and molybdate solution here used

${ }^{1}$ Abstract of a thesis presented for the degree of Bachelor of Science in Chemical Engineering, University of Missouri, Igo8. 